\title{
Colletotrichum siamense causing anthracnose in Bauhinia forficata subsp. pruinosa in Argentina
}

\author{
S Larran • J Vera Bahima • G Dal Bello • E Franco • \\ P Balatti
}

Received: 16 May 2014 / Accepted: 27 January 2015 /Published online: 12 February 2015

(C) Australasian Plant Pathology Society Inc. 2015

\begin{abstract}
Bauhinia forficata subsp. pruinosa is a common perennial tree species native to South America that belongs to the Fabaceae. In December 2010 and 2011, plants from a nursery located in the province of Buenos Aires, Argentina presented typical symptoms of anthracnose. We isolated from the lesions of diseased leaves a fungus that based on morphological as well as the ITS (KC132841) and $\beta$-tubulin sequences (KJ829534) was identified as Colletotrichum siamense. After 12 days leaves inoculated with the fungal spore suspension developed lesions similar to those observed in natural infections. The fungus was then re-isolated fulfilling Koch's Postulates. To our knowledge, this is the first report of Colletotrichum siamense causing anthracnose in Bauhinia forficata subsp. pruinosa in Argentina.
\end{abstract}

Keywords Colletotrichum siamense - Bauhinia forficata . Anthracnose · Colletotrichum gloeosporioides complex · Pezuña de vaca $\cdot$ Tree native $\cdot$ Fabaceae

Bauhinia forficata subsp. pruinosa is a common perennial tree species native to South America that belongs to the

S. Larran $(\bowtie) \cdot J$. V. Bahima $\cdot$ G. D. Bello $・$ E. Franco $\cdot$ P. Balatti Centro de Investigaciones de Fitopatología, Facultad de Ciencias Agrarias y Forestales, Universidad Nacional de La Plata (UNLP), 60 y 119, La Plata 1900, Bs As, Argentina

e-mail: silvinalar@gmail.com

J. V. Bahima

Consejo Nacional de Investigaciones Científicas y Técnicas (CONICET), Buenos Aires, Argentina

G. D. Bello $\cdot$ P. Balatti

Comisión de Investigaciones Científicas de la Provincia de Buenos Aires (CICBA), Buenos Aires, Argentina family Fabaceae. The tree is widely distributed mainly in tropical (Southern Brazil) and subtropical areas (Argentina), that are either free or have low risk of frosts (Burkart 1943). The tree has bilobed leaves and because of this is known as "pata de vaca". This, and its large white flowers, are distinctive of the genus Bauhinia (Fig. 1). The plant is a source of medical compounds and is also used as a shrubbery border plant (Burkart 1943; Cechimel Filho 2009). In December 2010 and 2011, within the area of La Plata, province of Buenos Aires, Argentina, nursery plants of B. forficata subsp. pruinosa that were routinely screened for diseases, presented circular or irregular, light brown necrotic lesions surrounded by a dark brown border, both in the center as well as the edges of the leaves (Fig. 1). Surface-sterilized disease leaf tissue was placed on Petri plates filled with potato dextrose agar (PDA) and incubated at $27{ }^{\circ} \mathrm{C}$. We obtained monosporic cultures of a fungus that produced gray to black mycelium, whitish at the top, with peach to orange concentric rings of acervuli. Conidia were single-celled, hyaline, cylindrical-straight, with rounded ends and measured 9.614.4 long $x$ 3-4.3 $\mu \mathrm{m}$ wide.

Genomic DNA of the fungus was isolated as described by Meinhardt el al. (1993). By means of a PCR with two primers ITS5 and ITS4 (White et al. 1990), a DNA fragment of the isolate, containing the 3 'terminal of the 18SrDNA, ITS1, the 5.8S rDNA, ITS2 and the 5 'terminal of the $28 \mathrm{~S}$ rDNA, was amplified in a $\mathrm{M} \& \mathrm{~J}$ Research Minithermocycler. Also the $\beta$-tubulin partial sequences were amplified by means of two pairs of primers (Glass and Donaldson 1995). Both the ITS and $\beta$-tubulin amplicons generated were sequenced by means of the dideoxy termination methods (Sanger et al. 1977) 
Fig. 1 Bauhinia forficata subsp. pruinosa: white flowers and bilobed leaves (left) and symptoms of anthracnose caused by Colletotrichum siamense (right)

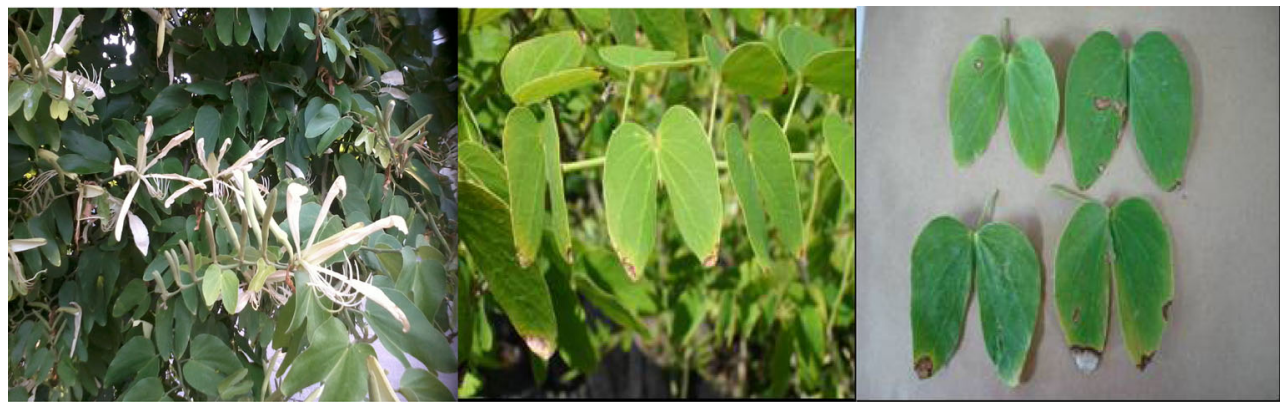

at Macrogen (Korea). The ITS (KC132841) and the partial $\beta$-tubulin sequences (KJ829534) were used to run a query against the QBank Database of Quarantine Plant Pests and Diseases (www.q-bank.eu). The results confirmed that the fungus belonged to the Colletotrichum gloeosporioides complex, within the Musae clade of Weir et al. 2012. Several species within the clade are known to form perithecia in agar culture. However, the morphological characteristics as well as the ITS and $\beta$-tubulin sequences, confirmed the identity of the isolate as Colletotrichum siamense (Hyde et al. 2009; Weir et al. 2012). Both sequences were 99.8 and 99,3\% homologous to those of Colletotrichum siamense.

Pathogenicity of the fungus was tested by inoculating healthy leaves of three plants of Bauhinia forficata subsp. pruinosa with a conidial suspension $\left(1 \times 10^{6}\right.$ spores/mL) until run-off according to a technique used by several authors (Wolcan and Larran 2000; Wright et al. 2006; Okryun et al. 2012). After inoculation leaves were covered with plastic bags for $48 \mathrm{~h}$ and kept at room temperature. Controls were the leaves of healthy plants that were wounded and sprayed with distilled water. After 12 days leaves inoculated with the fungal spore suspension developed lesions similar to those observed in natural infections. No symptoms were observed on non-inoculated control plants. Furthermore, we readily re-isolated the fungus from lesions on inoculated leaves, fulfilling Koch's Postulates. A culture of the isolate used in the pathogenicity test and taxonomic studies was deposited in the Culture Collection of the Centro de Investigaciones de Fitopatología (CIDEFI), Facultad de Ciencias Agrarias y Forestales, University of La Plata as CG2 (Email: cidefi@gmail.com).

Colletotrichum siamense has been cited as a pathogen of coffee berries, citrus, chilli and loquat in Thailand, China, India and Australia, respectively (Prihastuti and Hyde 2009; Cheng et al. 2013; James et al. 2014; Sharma and Shenoy 2013). To our knowledge this is the first report of $C$. siamense causing anthracnose in B. forficata subsp. pruinosa in Argentina.

\section{References}

Burkart AE (1943) Las leguminosas argentinas silvestres y cultivadas. Buenos Aires Acme Agency, SRL. Legumes, Pp. 590

Cechimel Filho V (2009) Chemical composition and biological potential of plants from the genus Bauhinia. Phytother Res 23:1347-1354

Cheng BP, Huang YH, Song XB, Peng AT, Ling JF, Chen X (2013) First report of Colletotrichum siamense causing leaf drop and fruit spot of Citrus reticulata Blanco cv. Shiyue Ju in China. Plant Dis Notes 11: 1508

Glass NL, Donaldson GC (1995) Development of primer sets designed for use with the PCR to amplify conserved genes from filamentous ascomycetes. Appl Environ Microbiol 61:1323-1330

Hyde KD, Cai L, Cannon PF, Crouch JA, Crous PW, Damm U, Goodwin PH, Chen H, Johnston PR, Jones EBG, Liu ZY, McKenzie EHC, Moriwaki J, Noireung P, Pennycook SR, Pfenning LH, Prihastuti H, Sato T, Shivas RG, Tan YP, Taylor PWJ, Weir BS, Yang YL, Zhang JZ (2009) Colletotrichum - names in current use. Fungal Divers 39:147-182

James RS, Ray J, Tan YP, Shivas RG (2014) Colletotrichum siamense, C. theobromicola and C. queenslandicum from several plant species and the identification of $C$. asianumin the Northern Territory, Australia. Aust Plant Dis Notes. doi:10.1007/s13314-014-0138-x

Meinhardt LW, Krishnan HB, Balatti PA, Pueppke SG (1993) Molecular cloning and characterization of a sym plasmid locus that regulates cultivar-specific nodulation of soybean by Rhizobium fredii USDA257. Mol Microbiol 9:17-29

Okryun C, Okhee C, Youn-Sig K, Jinwoo K, Jin-Hyeuk K (2012) Spot anthracnose disease caused by Colletotrichum gloeosporioides on tulip tree in Korea. Microbiología 40:82-84

Prihastuti LC, Hyde KD (2009) Characterization of Colletotrichum species associated with coffee berries in Chiang Mai, Thailand. Fungal Divers 39:98

Sanger F, Nicklen S, Coulson AR (1977) DNA sequencing with chainterminating inhibitors. Proc Natl Acad Sci U S A. 1977 Dec; 74(12): $5463-5467$

Sharma G, Shenoy BD (2013) Colletotrichum fructicola and C. siamense are involved in chilli anthracnose in India. Arch Phytopathol Plant Protect 47:1179-1194. doi:10.1080/03235408.2013.833749

Weir BS, Johnston PR, Damm U (2012) The Colletotrichum gloeosporioides species complex. Stud Mycol 73:115-180

White TJ, Bruns T, Lee S, Taylor J (1990) Amplification and direct seqencing of fungal ribosomal RAN genes for phylogenetics. PCR Protocols: A Guide to Methods and Applications. Academic Press Inc. Pp. 315-322

Wolcan S, Larran S (2000) First report of anthracnose caused by Glomerella cingulata on Passion fruit in Argentina. Plant Dis Notes 84:706. doi:10.1094/PDIS.2000.84.6.706A

Wright ER, Rivera MC, Mascarini A, Núñez LS, Gentile CM (2006) Florist's Cyclamen anthracnose caused by Colletotrichum gloeosporioides in Argentina. Australas Plant Dis Notes. doi:10.1071/DN06001 